\title{
Changing Horses and Hedging
}

\section{Günter Franke}

Department of Economics, University of Konstanz

\section{Introduction}

A firm chooses its investment policy conditional on a set of exogenous and endogenous parameters. Among the exogenous parameters are the prices of input factors, technology, customer demand, and market structure. The exogenous parameters usually are random. A given investment policy remains optimal as long as these parameters stay within certain ranges. Once these ranges are surpassed, the firm changes its investment policy, i.e. the firm changes horses. In a perfect, competitive capital market the horse change is independent of the firm's financing policy since the Fisher Separation holds. In the real world, capital markets are imperfect. Therefore the firm's financing policy affects its investment policy. For example, a firm with small financial resources may find it impossible to finance a major investment project, which appears to have a high market value, but is also subject to high risk. High-growth firms usually pay small or no dividends at all to increase the funds available for financing growth. Hence the firm's financing policy turns out to be important for the firm's investment policy.

The purpose of this paper is to analyze the interaction between a firm's investment and financing policy both of which depend on an exogenous risk factor which is driven by a given stochastic process. There exist financial derivatives on the exogenous risk factor which allow the firm to hedge the impact of the risk factor on the investment payoff. The firm has to determine the hedging policy as part of its financing policy. A particular issue of the hedging policy is its time horizon. For which time horizon should the firm hedge the investment payoffs against the exogenous risk factor? If hedging contracts are very long-term, then the firm can subsidize investment losses through hedging profits for a long time so that there is little financial pressure to change horses. If hedging contracts are short-term, then a firm with small financial resources is forced to react quickly when the exogenous risk factor deteriorates. Hence the time horizon of the hedging policy turns out to be important.

The paper illustrates this problem using the exchange rate as the exogenous risk factor. The firm exports to another country. If the exchange rate deteriorates, then the firm has the option to change its investment policy to improve its profits. It can relocate its production, for example, to the foreign country. This change requires a

$$
\text { Konstanzer Online-Publikations-System (KOPS) }
$$

URL: http://www.ub.uni-konstanz.de/kops/volltexte/2008/5381/

URL: http://www.ub.uni-konstanz.de/kops/volltexte/2008/5381/
URN: http://nbn-resolving.de/urn:nbn:de:bsz:352-opus-53811 
major initial outlay, which has to be financed by internal funds. Hence the firm has an incentive to generate sufficient funds for this situation through its hedging policy. The firm can, for example, sell a currency swap, which generates profits if the exchange rate deteriorates. The longer the swap maturity, the more profit is generated. On the other hand, if the exchange rate appreciates, the firm incurs swap losses. Therefore the firm optimizes the maturity of the swap. It will be shown how the hedging policy depends on the characteristics of the exchange rate process, the real investment option and the costs of financial distress.

The paper discusses some related literature in section 2. The base case of the analysis is presented in section 3 , the hedging optimization in section 4 . Section 5 concludes.

\section{Related Literature}

This section sketches the related literature, which is extensive since it covers various fields. First, there is the literature on real options. The basic models are well summarized in the books of Dixit and Pindyck (1994) and Trigeorgis (1996). Since real options are usually American options, the optimal timing of the exercise depends on the costs and benefits of deferring the exercise. The lower the cost of reversing the investment in case it turns out to be unprofitable, the smaller the time value of the option, making early exercise of the option more attractive (Friedl, 2002). Exporting can be considered an option; the optimal exercise of this option is analyzed in Franke (1991), Sercu and van Hulle (1992), Mello et al. (1995).

Second, there is a vast literature on hedging risks which also applies to hedging exchange rate risks. For static models of hedging exchange rate risk see AdamMüller (1995), for dynamic models see Mello et al. (1995).

Third, a strand of literature has focused on the interaction of investment and financing decisions. Myers and Majluf (1984) discuss this issue under asymmetric information. Mello and Parsons (1992) analyze how real investment decisions interact with debt valuation and closure decisions. Fries et al. (1997) consider entry and exit decisions in perfectly competitive markets and their impact on corporate debt.

Finally, there is a vast literature on agency problems related to free cash flow. Based on Jensen (1986), many papers argue that managers in firms with strong financial resources tend to work less efficiently than in firms with weak financial resources. Some of this literature is reviewed in Harris and Raviv (1991), Stulz (1990), and Shleifer and Vishny (1997).

\section{The Base Case}

In the base case, the firm operates in a perfect capital market. We consider a firm which produces some commodity for exports. The export market is characterized by monopolistic competition. The price at which the commodity is sold in the foreign market depends on the quantity sold by the firm and also on the quantity sold by its competitors. The latter quantity depends on the exchange rate and other factors, which are assumed to be non-random. Similarly, the quantity sold by the firm depends directly on the exchange rate and indirectly through the behavior of competitors. A higher exchange rate (= domestic currency units per foreign currency unit) induces the firm to raise its export volume. Therefore the export cash flow in domestic currency units is an increasing, convex function in the exchange rate (for more details see Franke, 1991).

If the exchange rate falls below the break-even point, then the cash flow becomes negative. Then, the firm has the option to stop exports, which may generate exit costs. We assume that the firm does not consider the exit option. Instead, it considers a switching option, i.e. the option to switch to a different product or a different production technology. For example, the firm could relocate its production from the domestic to the foreign country in order to reduce its production cost given a low exchange rate. Or the firm could outsource important parts of the production to low-cost-providers. Or the firm could redesign its products so as to economize on the domestic production components.

Switching is costly. It requires an outlay $I(\hat{w})$, which may depend on the exchange rate $\hat{w}$ at which the firm switches. We assume $I^{\prime}(\hat{w}) \geq 0$ and $I^{\prime \prime}(\hat{w}) \geq 0$. This outlay is the strike price of the switching option. We assume for simplicity that the firm switches only once and then retains this technology forever. The investment is assumed to be irreversible. The model is cast in continuous time. The current technology generates an instantaneous cash flow $c_{0}(w)$ in domestic currency. This cash flow neither depends on other risk factors nor on time. Switching at date $\hat{t}$ implies that the instantaneous cash flow $c_{n}(w)$ of the new technology replaces $c_{0}(w)(\forall t \geq \hat{t})$. This is tantamount to saying that the firm earns $c_{0}(w)$ forever and, in addition, $\Delta c(w) \equiv c_{n}(w)-c_{0}(w)$ from date $\hat{t}$ on.

The differential cash flow $\Delta c(w)$ is assumed to be declining and concave in $w$ (Figure 1). At the current exchange rate $w_{0}$, the current technology generates a higher cash flow than the new technology so that there is no reason to switch at present. 
Figure 1: The differential cash flow of the new versus the old technology; ( $w_{0}$ is the current exchange rate, $\underline{w}$ the break even-rate.)

$\Delta c(w)$

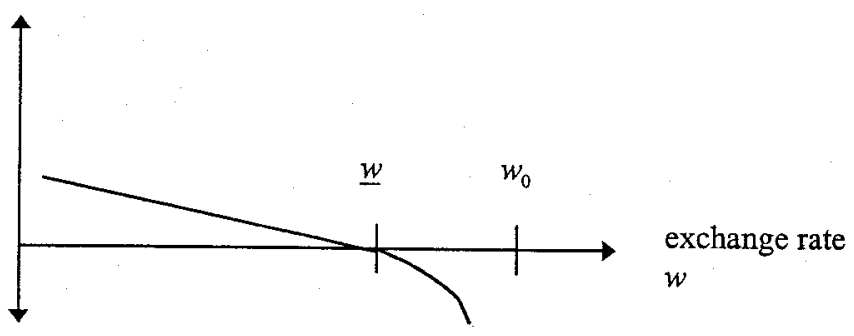

We assume that the exchange rate is the only exogenous risk factor. In the absence of agency problems and financial constraints, the firm chooses the switching exchange rate so as to maximize its market value. The cash flows of the firm are discounted at the risk-adjusted rate $r$, which is assumed to be independent of the exchange rate and the switching decision. In this setting switching is only driven by the exchange rate level. The lower the exchange rate, the more favorable switching is. We assume that the exchange is driven by a homogeneous process, i.e. the exchange rate process, starting at some date $t$, depends only on $w_{t}$, the date- $t$-exchange rate, but not on $t$ or on other observable date- $t$ parameters. Hence there exists an exchange rate $\hat{w}$ at which switching is optimal. The switching date, $\hat{t}$, is the date at which the exchange rate $w_{t}$, starting at $w_{0}\left(w_{0}>\hat{w}\right)$, hits the lower level $\hat{w}$ for the first time. Hence $\hat{t}=t(\hat{w})$ is the first passage time.

Given the stochastic process of the exchange rate, let $f(t(\hat{w}))$ denote the probability density of the first passage time $t(\hat{w})$. It is assumed to be twice differentiable in $t$ and in $\hat{w}$. The date-zero market value of the firm, $V_{0}$, is given by

$$
\begin{aligned}
V_{0}= & \int_{0}^{\infty} E_{0}\left(c_{0}\left(w_{t}\right)\right) \exp (-r t) d t \\
& +\int_{0}^{\infty}\left[\int_{t(\hat{w})}^{\infty} E_{t(\hat{w})}\left(\Delta c\left(w_{\tau}\right)\right) \exp (-r(\tau-t(\hat{w}))) d \tau-I(\hat{w})\right] \\
& f(t(\hat{w})) \exp (-r t(\hat{w})) d t .
\end{aligned}
$$

The first term is the expected value of the cash flows from the current technology at date $t$, discounted at the rate $r$ and integrated over $t \in[0, \infty)$. The second term is the market value of the switching option. $\Delta c\left(w_{\tau}\right)$ is the differential cash flow at date $\tau, \tau>t(\hat{w})$, and $E_{t(\hat{w})}\left(\Delta c\left(w_{\tau}\right)\right)$ the expectation of $\Delta c\left(w_{\tau}\right)$ as of the switching date. This expectation depends on the distribution of $w_{\tau}$, conditional on $w_{t}=\hat{w}$ at $t=t(\hat{w})$. Hence this expectation varies with $\tau$. It is discounted, first, to the switching date $t(\hat{w})$. The outlay $I$ is subtracted. Hence the squared bracket shows the market value of the horse change at the switching date $t(\hat{w})$. This market value is denoted $P(\hat{w})$. It is discounted then to date 0 and multiplied by the first passage time-probability density. Since this time is distributed over $t \in[0, \infty)$, we integrate over this period.

Note that under our assumptions $P(\hat{w})$ depends on $\hat{w}$, but not on $t(\hat{w})$. For notational simplicity, $t=t(\hat{w})$, so that $f(t)$ is the first passage time-probability density. Then the firm chooses the switching exchange rate $\hat{w}$ so as to maximize the date-zero expected market value of switching

$$
P(\hat{w}) \int_{0}^{\infty} \exp (-r t) f(t) d t .
$$

Differentiating equation (2) with respect to $\hat{w}$ yields

$$
P^{\prime}(\hat{w}) \int_{0}^{\infty} \exp (-r t) f(t) d t+P(\hat{w}) \int_{0}^{\infty} \exp (-r t) \frac{\partial f(t)}{\partial \hat{w}} d t=0
$$

From our assumptions on $\Delta c(w)$ and $I(\hat{w}), P^{\prime}(\hat{w})<0$. An increase in $\hat{w}$ raises the first passage-probability for low values of $t$ and lowers it for high values of $t$, hence the second integral is positive, i.e. the expected discount factor increases in $\hat{w}$. Hence $P(\hat{w})>0$ is required for (3) to hold, the switching option is exercised only when it is in the money.

For a maximum the second derivative with respect to $\hat{w}$ must be negative at the optimal switching rate. This condition holds if $P^{\prime \prime}(\hat{w})<0$ and the expected discount factor is concave in $\hat{w}$.

The intuition behind the first order condition (3) is as follows. First note that $P(\hat{w})>0$. Hence the option is not exercised immediately when it comes into the money. Instead the firm defers exercise until the option is deeper in the money since exercise of the option destroys its time value. This implies also that the switching rate $\hat{w}$ is smaller than the break even-rate $\underline{w}$ (except for the case of a strongly negative drift in the exchange rate).

In the optimum, the marginal cost of raising $\hat{w}$, i.e. exercising the option earlier must equal the marginal benefit. The marginal cost, $\left|P^{\prime}(\hat{w})\right|$, is due to the fact that, conditional on a higher switching rate, the probability of positive cash flows $\Delta c(w)$ is reduced and that of negative cash flows is increased. The marginal benefit is a pure discounting effect. Earlier exercise raises the discounted value of $P(\hat{w})$.

The optimal switching rate depends on the exchange rate process. The time value of the option increases with exchange rate volatility, given an additive Brownian motion without drift. Hence a higher volatility would induce the firm to delay exercise, i.e. lower $\hat{w}$. 
If the exchange rate follows an Ornstein-Uhlenbeck process, then the mean reversion reduces the standard deviation of future exchange rates. Whether this lowers $\hat{w}$, depends also on the long run-equilibrium rate $w_{e}$ relative to the break evenrate $\underline{w}$. If $w_{e}>\underline{w}$, then the firm will be more cautious in exercising the option because $\Delta c(w)$ will be negative with high probability. Hence $\hat{w}$ will be depressed. If, however, $w_{e}<w$, then the time value of the option will be small, because $w>\underline{w}$ is rather unlikely. Therefore $\hat{w}$ will be fairly high.

\section{The Hedging Decision}

\subsection{The Setup}

So far we have assumed that the firm has sufficient financial resources. It optimizes its investment policy without regard to financial distress concerns so that the Fisher Separation holds. Now we give up the assumption of perfect capital markets. We assume that the firm may run into financial distress and ask what this implies for its hedging policy. The firm is solvent at date 0 and has small financial reserves $R_{0}$ at date 0 . These reserves are defined as the firm's monetary assets minus its monetary liabilities. The firm cannot raise new equity. But it can prolong maturing debt.

It prefers to hedge exchange rate risk by trading exchange rate derivatives which do not absorb cash at date 0 . We shall concentrate mostly on trading currency swaps. The associated transaction costs are fairly small and the use of swaps does not require a sophisticated technology. The initial margin requirement is satisfied through pledging some assets. Variation margin requirements are financed through cash in-and outflows. The cash flow generated by hedging at date $t$ depends on the exchange rate $w_{t}$ and is denoted $h_{t}\left(w_{t}\right)$.

In our model, the purpose of hedging is to reduce the firm's expected cost of financial distress (distress cost). Consistent with Froot et al. (1993), we assume that distress is inversely related to financial reserves. The lower these reserves are, the higher is the distress cost. The firm's owners and creditors know these reserves and make the terms of their money supply dependent on the level of these reserves. The reserves at date $t, R_{t}$, are given by

$$
R_{t}=R_{0} \exp (r t)+\int_{0}^{t}\left[c_{0}\left(w_{\tau}\right)+h_{\tau}\left(w_{\tau}\right)\right] \exp (r(t-\tau)) d \tau+H_{t}\left(w_{t}\right)
$$

before the firm has exercised the switching option. $H_{t}\left(w_{t}\right)$ is the date-t market value of the hedging contract which depends on the date- $t$ exchange rate. This market value is 0 at date 0 , diverges from zero later and returns to 0 at maturity. We include the market value $H_{t}\left(w_{t}\right)$ in the financial reserves because the firm could liquidate the swap and, thus, earn a cash flow $H_{t}\left(w_{t}\right)$, if positive, or pay $H_{t}\left(w_{t}\right)$, if negative. We assume that investors always know $H_{t}\left(w_{t}\right)$ and therefore include it in the financial reserves. The interest effects of the variation margin are ignored.

If the firm exercises its option at date $t_{1}$, then the reserves for $t>t_{1}$ are given by

$$
\begin{aligned}
& R_{t}=R_{0} \exp (r t)+\int_{0}^{t_{1}}\left[c_{0}\left(w_{\tau}\right)+h_{\tau}\left(w_{\tau}\right)\right] \exp (r(t-\tau)) d \tau-I(\hat{w}) \exp \left(r\left(t-t_{1}\right)\right) d \tau \\
& +\int_{t_{1}}^{t}\left[c_{0}\left(w_{\tau}\right)+\Delta c\left(w_{\tau}\right)+h_{\tau}\left(w_{\tau}\right)\right] \exp (r(t-\tau)) d \tau+H_{t}\left(w_{t}\right) .
\end{aligned}
$$

One might argue that also future cash flows from exporting should be included in $R_{t}$. But theses cash flows are highly uncertain and, therefore, we assume that investors are unwilling to include them. ${ }^{1}$

The lower the financial reserves, the higher are the cost of financial distress. The instantaneous distress cost $k\left(R_{t}\right)$ is assumed to be positive, declining and convex in $R_{t}$ (see also Froot et. al 1993). For high levels of $R_{t}, k\left(R_{t}\right)$ approaches zero. The market value of the firm at date $0, V_{00}$, equals the market value of the cash flows in equation (1), $V_{0}$, minus the expected costs of financial distress

$V_{00}=V_{0}-\int_{0}^{\infty} E_{0}\left(k\left(R_{t}\right)\right) \exp (-r t) d t$

\subsection{The Optimal Hedging Maturity for a Given Investment Policy}

First, we assume that the real activities of the firm are given and independent of its hedging policy. The firm can buy a hedging instrument with maturity $T$. Suppose initially that the firm can buy a hedging instrument which perfectly hedges the operating exchange risk at every date $t, t \leq T$. Moreover, assume that the instrument is fair priced, i.e. the risk premium in the currency market is zero. Then a perfect hedge with an infinite maturity would be optimal if the financial reserves at any date $t$ were independent of the market value of the instrument, $H_{t}\left(w_{t}\right)$.

This is similar to accounting practices. In the balance sheet the changes in market values of financial contracts need to be recognized as profits/losses. But future profits/losses from selling commodities are not recognized. Hence even if the profits/losses from hedging and from sales are likely to balance each other, this is not recognized in the income statement. Therefore hedging may create a strong profit risk (Franke, 1992). 
Then the financial reserves at any date $t$ would be independent of the exchange rate movement. As the cost of financial distress-function is convex, the expected cost of financial distress would be minimal if financial reserves were nonstochastic.

Since, however, financial reserves include the market value of the instrument, $H_{t}\left(w_{t}\right)$, this term creates a high $R_{t}$ risk and, hence, high expected distress cost. If the maturity of the hedge is infinite, then economic exchange risk would be hedged perfectly, but the market value of the instrument would be extremely volatile generating perhaps large negative values and, thus, a huge distress cost. Because of the implied high expected distress cost a hedge with infinite maturity cannot be optimal although economic risk would be perfectly hedged. Hence hedging economic exchange risk is not viable.

One alternative is to follow a dynamic hedging policy which at every date $t$ hedges only the exchange risk over the next moment $(t, t+d t)$ If the export activities for the next moment are contractually fixed, then hedging only the risk from these activities is the same as hedging the transaction risk dynamically. This hedging policy provides almost no hedge of the economic exchange risk since it is a myopic hedging policy. It does not hedge the impact of the exchange rate movement on $V_{t+d t}\left(w_{t+d t}\right)$. Hence this hedging policy is ineffective.

A second alternative is to hedge dynamically at any date $t$ the transaction risk over the next moment and the $V_{t+d t}\left(w_{t+d t}\right)$ risk. This policy effectively hedges the economic risk and, thus, is not viable as stated before.

Therefore the hedging policy has to compromise. It can cover a limited time period. Under the assumption that all operating exchange risk is fully covered until date $T$ (full hedge) and nothing is covered thereafter, the optimal coverage period $T$ is derived from minimizing the expected distress cost.

$$
\begin{aligned}
& \min _{T} \int_{0}^{T} E_{0}\left[k\left\{R_{0} \exp (r t)+\int_{0}^{t} c_{\theta} \exp (r(t-\theta)) d \theta+H_{t}\left(w_{t}\right)\right\}\right] \exp (-r t) d t \\
& +\int_{T}^{\infty} E_{0}\left[k\left\{R_{T} \exp (r(t-T))+\int_{T}^{t} c_{\theta}\left(w_{\theta}\right) \exp (r(t-\theta)) d \theta\right\} \exp (-r t) d t\right]
\end{aligned}
$$

$c_{\theta}$ is the cash flow at date $\theta$ from real activities. For $\theta<T$, this cash flow is independent of $w_{\theta}$ since it is perfectly hedged. After date $T$, it is fully exposed to exchange rate risk. $R_{T}$ is the non-random amount of financial reserves at date $T$,

$$
R_{T}=R_{0} \exp (r T)+\int_{0}^{T} c_{\theta}(\exp (r(T-\theta))) d \theta
$$

This amount is independent of the exchange rate movement in the time interval $[0, T]$ because of the perfect hedge and because of $H_{t}=0$ for $t \geq T$.
Differentiating (7) with respect to $T$ yields the first order condition.

$$
\begin{aligned}
& \int_{0}^{T} E_{0}\left[k^{\prime}\left(R_{t}\right) \frac{d H_{t}\left(w_{t}\right)}{d T}\right] \exp (-r t) d t \\
& +\int_{T}^{\infty} E_{0}\left[k^{\prime}\left(R_{t}\right)\left(c_{T}-c_{T}\left(w_{T}\right)\right)\right] \exp (-r t) d t=0
\end{aligned}
$$

with $k^{\prime}\left(R_{t}\right) \equiv d k\left(R_{t}\right) / d R_{t}<0$. The first term in equation (9) is the expected marginal distress cost in the coverage period $[0, T]$ due to a marginal increase in hedging maturity. The second term is the expected marginal distress cost after the coverage period due to replacing the non-hedged cash-flow $c_{T}\left(w_{T}\right)$ by the hedged cash flow $c_{T}$. The second term is negative since $E_{0}\left(c_{T}-c_{T}\left(w_{T}\right)\right)=0$ and $k\left(R_{t}\right)$ is convex so that the expected distress cost after the coverage period is reduced. Hence an optimal maturity requires the first term in equation (9) to be positive.

For illustration, consider a plain vanilla-currency swap at date 0 such that $y$ foreign currency units are sold against $x$ home currency units at every date $\theta \in[0, T]$. This creates a perfect hedge if the firm earns always $y$ foreign currency units irrespective of the exchange rate. Given constant risk-free rates in the home and in the foreign currency, $r_{I}$ and $r_{F}$, the market value of the swap at date $t$ is

$$
H_{t}\left(w_{t}\right)=-y w_{t} A F\left(r_{F}, T-t\right)+x A F\left(r_{I}, T-t\right)
$$

with

$$
A F(r, T-t) \equiv \int_{0}^{T-t} \exp (-r \theta) d \theta
$$

being the annuity factor for the discount rate $r$ and the maturity $(T-t)$.

Since $H_{0}\left(w_{0}\right)=0$,

$$
y w_{0} A F\left(r_{F}, T\right)=x A F\left(r_{I}, T\right) .
$$

Hence

$$
\frac{d H\left(w_{t}\right)}{d T}=y\left[-w_{t} \exp \left(-r_{F}(T-t)\right)+\frac{w_{0} \exp \left(-r_{I}(T-t)\right)}{A F\left(r_{F}, T\right) / A F\left(r_{I}, T\right)}\right]
$$

Consider the simplest case in which $r_{F}=r_{I}$ and $E_{0}\left(w_{t}\right)=w_{0} \forall t$. Then

$$
\frac{d H\left(w_{t}\right)}{d T}=y \exp \left(-r_{F}(T-t)\right)\left[-w_{t}+w_{0}\right]
$$


Moreover, approximate $k^{\prime}\left(R_{t}\right)$ by a linear function $k^{\prime}\left(R_{t}\right)=a+E_{0}\left[k^{\prime \prime}\left(R_{t}\right)\right] R_{t}$.

Since, for $t<T, R_{t}$ is composed of a non-random term and $H_{t}$, it follows from (12) that

$$
\begin{aligned}
E_{0}\left[k^{\prime}\left(R_{t}\right)\right. & \left.\frac{d H_{t}\left(w_{t}\right)}{d T}\right]=\operatorname{cov}_{0}\left[k^{\prime}\left(R_{t}\right) ; \frac{d H_{t}\left(w_{t}\right)}{d T}\right] \\
= & y \exp \left(-r_{F}(T-t)\right) E_{0}\left[k^{\prime \prime}\left(R_{t}\right)\right] \operatorname{cov}\left(H_{t},-w_{t}\right) \\
= & y^{2} \exp \left(-r_{F}(T-t)\right) E_{0}\left[k^{\prime \prime}\left(R_{t}\right)\right] A F\left(r_{F}, T-t\right) \sigma_{0}^{2}\left(w_{t}\right)
\end{aligned}
$$

with $\sigma_{0}^{2}\left(w_{t}\right)$ being the variance of $w_{t}$ as of date 0

Since we assume $c_{\theta}\left(w_{\theta}\right)=y w_{\theta}$ and $E_{0}\left(w_{\theta}\right)=w_{\theta}, c_{T}-c_{T}\left(w_{T}\right)=y\left[w_{0}-w_{T}\right]$ and

$$
\begin{aligned}
E_{0}\left[k^{\prime}\left(R_{t}\right)\right. & \left.\left(c_{T}-c_{T}\left(w_{T}\right)\right)\right]=y \operatorname{cov}_{0}\left[k^{\prime}\left(R_{t}\right),-w_{T}\right] \\
& =y^{2} \operatorname{cov}_{0}\left(\int_{T}^{t} E_{0}\left[k^{\prime \prime}\left(R_{t}\right)\right] w_{t} \exp (r(t-\theta)) d \theta,-w_{T}\right) \\
& =-y^{2} \int_{T}^{t} E_{0}\left[k^{\prime \prime}\left(R_{t}\right)\right] \operatorname{cov}\left(w_{\theta}, w_{T}\right) \exp (r(t-\theta)) d \theta
\end{aligned}
$$

$\operatorname{cov}_{0}\left(w_{\theta}, w_{T}\right)$ is the covariance between $w_{\theta}$ and $w_{T}$ as of date 0. Inserting (13) and (14) in the first order condition (9) yields

$$
\begin{aligned}
\exp \left(-r_{F} T\right) \int_{0}^{T} E_{o}\left[k^{\prime \prime}\left(R_{t}\right)\right] A F\left(r_{F}, T-t\right) \sigma_{0}^{2}\left(w_{t}\right) \exp \left(\left(r_{F}-r\right) t\right) d t \\
=\int_{T}^{\infty} E_{o}\left[k^{\prime \prime}\left(R_{t}\right)\right] \int_{T}^{t} \operatorname{cov}_{o}\left(w_{\theta}, w_{T}\right) \exp (-r \theta) d \theta d t
\end{aligned}
$$

The left-hand side of (15) is zero for $T=0$ and increases with $T$ in some range and may decline thereafter. The right-hand side of (15) declines in $T$. Thus, there exists an interior minimum of expected distress costs.

The intuition behind this result is straightforward. Swaps with long maturity can have strongly negative market values at dates $t<T$, in particular at those dates for which $A F\left(r_{F}, T-t\right) \sigma_{0}^{2}\left(w_{t}\right)$ is high. This creates high expected distress costs. In order to avoid these, the firm reduces the swap maturity. There is a cost to this in the time after maturity. A shorter swap maturity raises the volatility of the reserves after maturity since the exchange risk is hedged only for a shorter time period. For the optimal swap maturity both effects match each other. The optimal swap maturity tends to be shorter, the higher the discount rate $r$ is. This follows from the observation that the benefits from extending the swap maturity in the period $[T, \infty)$ are more strongly exposed to discounting than the costs in the period $[0, T]$.

Whether a higher exchange rate volatility induces a longer swap maturity, depends on the assumed exchange rate process. If all standard derivations $\sigma_{0}\left(w_{t}\right)$ grow at the same rate leaving the autocorrelations the same, then the optimal maturity remains the same. If $\sigma_{0}\left(w_{t}\right)$ increases more in the early than in the late periods, then the optimal maturity declines since the marginal cost of extending maturity increases more than the marginal savings.

Whether a financially sound firm would take a longer swap position, depends on the convexity of the distress cost function. If this was constant, then financial reserves would have no impact. If convexity declines in $R_{t}$ (which appears reasonable to assume since for $R_{t} \rightarrow \infty$ we have $k\left(R_{t}\right) \rightarrow 0$ ), then a firm with high financial reserves $R_{0}$ would choose a longer maturity than a firm with low reserves. This follows since for a firm with strong initial reserves $E\left[k_{t}^{\prime \prime}\left(R_{t}\right)\right]$ tends to increase over time more strongly than for a firm with low initial reserves. Thus, the marginal cost of a maturity extension is relatively smaller for a sound financial firm.

The problem of using a swap as a hedging instrument is that the market value declines linearly in the exchange rate so that the market value may be strongly negative inducing high distress costs. Therefore financially weak firms should hedge with asymmetric contracts such that the market value $H_{t}$ declines in a convex manner in the exchange rate $w_{t}$. Hence strongly negative market values can be avoided. Such a hedging policy is much more sophisticated.

So far we have considered a policy of buying a hedging contract at date 0 only. A more demanding policy is a dynamic hedging policy such that the firm can adjust its hedge position from time to time and extend the coverage period gradually more and more into the future. The adjustment would depend on the actual financial reserves and on the actual exchange rate. The higher the financial reserves are, the more new long-term swaps would the firm buy. But this depends also on the prospective exchange rate movement. If the exchange rate is high and meanreverting, then the probability of the exchange rate declines is rather high so that the costs of financial distress in these situations get a higher weight.

\subsection{The Interaction between Hedging Policy and Investment Policy}

So far we have assumed a given investment policy, independent of the hedging policy. It is well known that hedging policy has an impact on investment policy if the Fisher-Separation does not hold. For example, a risk averse firm tends to 
reduce its export volume if it cannot perfectly hedge the exchange rate risk. In this paper we do not consider risk aversion effects, but concentrate on the costs of financial distress. Therefore the interaction between investment and hedging policy is driven by the costs of financial distress. Since the financial reserves depend on the investment and financing policy, both interact through the costs of financial distress.

In the following we discuss the interaction with switching, with estimation risk, with agency problems, and with competition.

\subsubsection{Interaction with Switching}

Suppose that in the absence of distress costs the firm would switch at the exchange rate $\hat{w}$. Financing the switch is difficult for two reasons. First, before switching, the firm's export activities generate negative cash flows if $\hat{w}$ is smaller than the break even rate of the current technology (Figure 1). This is not a problem if these negative cash flows are overcompensated by positive cash flows from hedging. Second, the total investment outlay $I(\hat{w})$ needs to be financed. Hedging this out flow is quite difficult. One could think of an American digital option which pays $I(\hat{w})$ whenever $w$ first hits the level $\hat{w}$. But such an option would be quite expensive.

Suppose that the firm can only hedge through swaps. Then the cash outflow $I(\hat{w})$ creates an incentive to take a larger swap position if the swap is in the money at the switching rate $\hat{w}$. Otherwise the firm takes a smaller swap position

How does the firm adjust the switching rate $\hat{w}$ ? Switching now does not only depend on the exchange rate, but also on the financial reserves. If theses are high then the optimal switching rate is similar to the case of no distress costs. If financial reserves are very low, then the firm may delay switching hoping that the exchange rate will appreciate again, thereby avoiding a very high immediate distress cost.

In general, the cash outflow $I(\hat{w})$ raises the immediate distress cost, but reduces the expected distress cost in the long run through higher cash inflows from the new export technology. The smaller the financial reserves are, the stronger is the incentive to delay switching. The option to wait appears attractive. However, waiting may also make things worse through accumulating additional negative cash flows and, thereby, making switching even more costly. Then waiting is also costly.

If the investment outlay $I(\hat{w})$ declines in $w$, then scarce financial resources would urge the firm to switch earlier at a higher rate so as to dampen distress costs. If $I(w)>0$, then the delay of switching would be reinforced.

\subsubsection{Interaction with Estimation Risk}

So far we have assumed that the firm has a precise understanding of the exchange rate process. Therefore, when the exchange rate hits the level $\hat{w}$, the firm switches. In reality, our understanding of exchange rate processes is quite limited. Even if the type of exchange rate process is known, then there exists a substantial risk in estimating the parameters of the process. This risk has an impact on the switching rate $\hat{w}$, even in the absence of distress costs. Since $\hat{w}<\underline{w}$, estimation risk implies that, ceteris paribus, $\operatorname{Prob}_{t_{1}}\left(w_{t}>w\right)$ increases for $t>t_{1}$, i.e. the date $t_{1}$-probability of crossing the break even-rate increases and, thus, raises the time value of the switching option. Therefore, estimation risk lowers the switching rate $\hat{w}$. This is in line with common sense: If the signals received by the firm are less reliable, then the firm waits for more confirming signals before taking action. In our setting, a further decline in the exchange rate is required to confirm the pessimistic exchange rate view.

Now consider the interaction between switching and hedging policy. The hedging policy needs to be adjusted to the lower switching-exchange rate. If the lower rate implies additional cash outflows between the first passage time of the old and of the new switching rate, the optimal swap position should increase so as to generate higher financial reserves at the switching date. Since the swap is in the money, given a decline in exchange rates, the swap adds to the financial reserves and thus, lowers the expected distress costs.

Again, as in the previous section, $I(w)<[>] 0$ would induce the firm to raise [lower] $\hat{w}$ so as to reduce the distress cost.

\subsubsection{Interaction with Switching and Agency Problems}

Now we ignore estimation risk and, instead, consider agency problems. The agency problem is defined as follows. Switching requires a major management effort and also creates tensions with other stakeholder groups like employees if some of them lose their job or suppliers are afraid of losing sales. In any case, management incurs a switching burden for which it may not get compensation. Then management dislikes this burden and is happy to postpone it to the future. If the shareholders do not take precautionary action against this delay, switching will be delayed by setting a lower switching rate.

The delay is facilitated in the case of strong financial reserves because investors then can put little pressure on management. Thus, management can subsidize cash outflows from exports through cash inflows from monetary assets.

In addition, anticipating the lower switching rate and the, perhaps, additional cash outflows, managers may buy more swaps in order to obtain protection against these outflows. Thus, they subsidize these outflows through cash inflows from 
hedging. This subsidization reduces the expected costs of financial distress, but it represents a waste of money since it reduces the value of the firm.

For the shareholders, this behavior may be difficult to infer from the firm's overall cash flows since the cash inflows from hedging may overcompensate the cash outflows from the switching delay. Thus, hedging provides camouflage for the management such that the delay goes unnoticed.

This agency behavior may induce the shareholders to constrain the extent of hedging through constraining the number and the maturity of the swaps. This would not only make the cash outflows in case of low exchange rates more visible, but also raise the expected distress costs. Both effects tend to constrain agency behavior.

\section{Summary}

This paper analyzes the interaction between switching investments and hedging. First, the paper shows that hedging economic risk is not optimal in a world with financial distress costs. We assume that financial distress costs are a declining convex function in the level of financial reserves. These reserves include the market value of outstanding hedging contracts, but not the future cash flow prospects from real activities of the firm because these are highly uncertain. As a consequence, very long-term hedging contracts would protect the firm against economic risk, but generate high expected distress costs because the hedging contracts might have very low, negative values. This explains why firms hedge only for rather short periods of time.

These arguments are illustrated by an exporting firm subject to exchange rate risk. This firm has the option to switch to another investment technology when the exchange rate deteriorates. Given a firm with weak financial reserves, switching is likely to be delayed to avoid the immediate high distress cost generated by the investment outlay hoping that the exchange rate appreciates again and the distress cost is reduced.

But the result is ambiguous. Switching earlier may avoid some negative cash flows from the current technology and, thus, alleviate the financing of the investment outlay.

Switching is delayed by estimation risk. If the exchange rate process is not known, then the firm waits for more confirming signals before it switches. This induces the firm to hedge more.

Agency behavior of managers has different facets. If the firm has strong financial reserves, then managers may want to defer the burden associated with switching. They can use the revenues from existing monetary assets to show "good" profits.
Managers can also hedge more and use the hedging profits to subsidize losses from real activities. The overall profit still appears "good" although money is wasted.

\section{References}

Adam-Müller, A. (1995): Internationale Unternehmensaktivität, Wechselkursrisiko und Hedging mit Finanzinstrumenten. Physica, Heidelberg

Dixit, A., Pindyck, R. (1994): Investment Under Uncertainty. Princeton University Press, Princeton

Franke, G. (1991): Exchange Rate Volatility and International Trading Strategy. Journal of International Money and Finance 10, 292-307

Franke, G. (1992): Uncertain Perception of Economic Exchange Risk and Financial Hedging. Managerial Finance 18, No. 3/4, 53-70

Friedl, G. (2002): Sequential Investment and Time to Build. Schmalenbach Business Review 54, 58-79

Fries, S., Miller, M., Peraudin, W. (1997): Debt Pricing in Industry Equilibrium. Review of Financial Studies 10, 39-68

Froot, K., Scharfstein, D., Stein, J. (1993): Risk Management: Coordinating Investment and Financing Decisions. Journal of Finance 48, 1629-1658

Harris, M., Raviv, A. (1991): The Theory of Capital Structure. Journal of Finance 46, 297-355

Jensen, M. (1986): Agency Costs and Free Cash Flow, Corporate Finance and Takeovers American Economic Review 76, 323-329

Mello, A., Parsons, J. (1992): The Agency Costs of Debt. Journal of Finance 47, 1887-1904

Mello, A., Parsons, J., Triantis, A.J. (1995): An Integrated Model of Multinational Flexibility and Financial Hedging. Journal of International Economics 39, 27-51

Myers, S., Majluf, N. (1984): Corporate Financing And Investment Decisions When Firms Have Information That Investors Do Not Have. Journal of Financial Economics 13, $187-221$

Sercu, P., van Hulle, C. (1992): Exchange Rate Volatility, International Trade and the Value of Exporting Firms. Journal of Banking and Finance 16, 155-182

Shleifer, A., Vishny, R. (1997): A Survey of Corporate Governance. Journal of Finance 52 737-783

Stulz, R. (1990): Managerial Discretion and Optimal Financing Policies. Journal of Financial Economics 26, 3-27

Trigeorgis, L. (1996): Real Options. MIT Press, Cambridge MA 